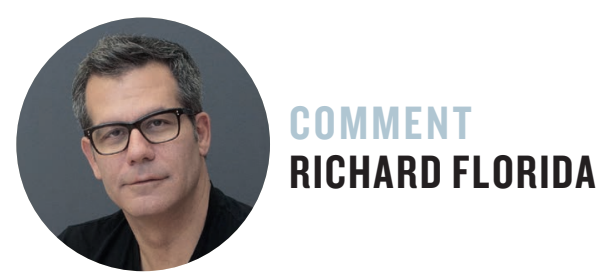

\title{
WHERE THE STREETS ARE PAVED WITH IDEAS
}

\section{Most of the world's research and entrepreneurship is concentrated in a few megacities.}

I nnovation is geographically uneven. The world's 40 richest mega-regions - expansive conurbations such as the Boston-New York-Washington DC corridor, Greater London, or the passage that runs from Shanghai to Beijing - account for more than $85 \%$ of the world's patents, and $83 \%$ of the most-cited scientists. And yet, only $18 \%$ of the world's population lives in them.

Innovators are crowding into increasingly smaller strips of real estate. In the 1970s and 1980s, large companies and high-tech start-ups were predominantly based in suburban office parks such as Silicon Valley in northern California; the Route 128 suburbs outside Boston, Massachusetts; or the suburbs of Austin, Texas, and Seattle, Washington. Today, $57 \%$ of startups and $54 \%$ of venture capital investment in the United States are located in cities. In 2013, two neighbourhoods in downtown San Francisco each attracted more than a billion dollars in venture capital.

But though cities have surged as centres of science and technology, their innovative potential is under threat. Rising housing prices are pushing out the broad mix of creative people that drive innovation. Many researchers and graduate students can no longer afford to live close to their labs and are forced to commute ever longer distances. That sprawl inhibits the spontaneous exchanges that fuel new ideas. While much is made of artists, musicians, writers and other creative people being pushed out of increasingly expensive cities and urban centres, scientists and researchers upon whom technological innovation depends are being priced out too.

\section{METRO POLES}

The role of cities as knowledge and innovation centres is being further eroded by the rising gap between rich and poor, and the resentment that it engenders. Leading metropolises are splitting into smaller areas of concentrated advantage and larger swathes of concentrated disadvantage. This transformation of great cities into expensive playgrounds for the wealthy has led to a backlash against them from across the political spectrum. In the San Francisco Bay Area, for example, voices from the left are increasingly blaming technology companies, and their employees, for the gentrification and displacement of the local community. These objections embody a struggle of our urban age: even though inequality and economic segregation are higher in leading knowledge cities, these metropolises also propel the innovation and start-ups that power economic growth. Furthermore, these cities that progressive leaders claim are so objectionable also offer the highest level of tolerance for outsiders and provide the most opportunities for upward economic mobility for the disadvantaged.

\section{POPULIST THREAT}

Even more worrying for cities is the growing sense of populist resentment from the right. Populist uprisings in the US and across Europe target knowledge, ideas and the urban elite. They are hostile towards science itself, seeking to discredit facts and branding universities as the enemy. They aim to reduce, or even eliminate, government funding for scientific research. Perhaps most damaging, they seek to limit the influx of talented foreign-born faculty and students that helps create the diverse, open-minded environment that fuels scientific and technological innovation.

President Donald Trump's efforts to clamp down on immigration and reduce public funding for scientific research represent serious threats to knowledge and discovery across US cities, universities and the nation as a whole. These resentment-driven policies could lead to a shift in the concentration of knowledge and innovation to other cities and regions that remain more open, such as those in Canada, as has happened in the past.

It's time we realized that the progress of science and technology, and our economy and society broadly, relies on the advance of knowledge and its clustering in cities. We need to continue to nurture and invest in both.

Richard Florida is a professor at the University of Toronto, distinguished fellow at New York University, and the co-founder and editor-atlarge of The Atlantic's CityLab.

\section{VENTURE CAPITAL INVESTMENT BY CITY}

More than half of venture capital invested in 2012 went to 10 cities. The United States is home to the top six metros and eight of the top 10. Taken together, these six metros - San Francisco, San Jose, Boston, New York, Los Angeles and San Diego - account for roughly $45 \%$ of total global investment, and $86 \%$ of the top 10 .

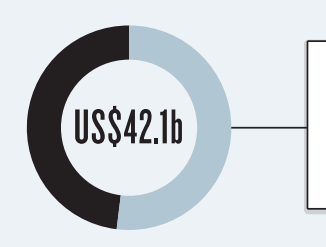

TOP 10: 52\% - US\$21.9h

10 cities received $52 \%$ of the total venture capital invested in 2012 , amounting to US $\$ 21.9$ billion of US $\$ 42.1$ billion. Below is a breakdown of the funds invested in the top 10 cities.

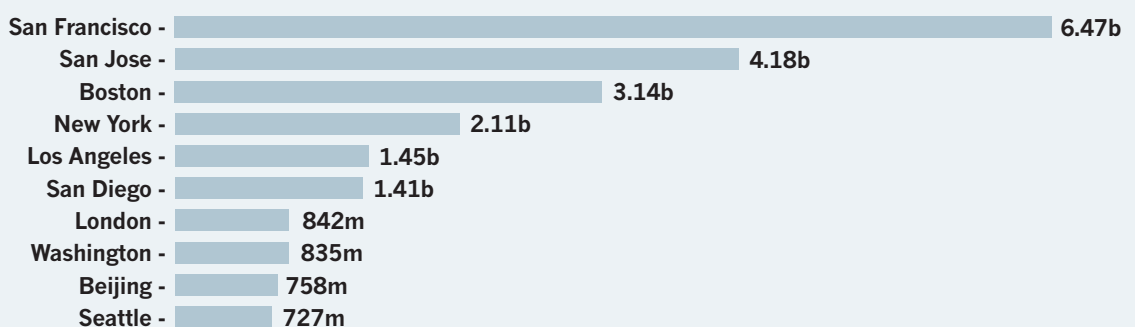

